\title{
Protein Intake Among Patients with Insulin-Treated Diabetes is Linked to Poor Glycemic Control: Findings of NHANES Data
}

\author{
Hiba Bawadi $\mathbb{D}^{\prime}$, Nahla Al-Bayyari $\mathbb{D}^{2}$, Reema Tayyem (D)', Zumin Shi $\mathbb{D}^{\prime}$ \\ 'Department of Human Nutrition and Food Science, College of Health Sciences, QU-Health, Qatar University, Doha, Qatar; ${ }^{2}$ Department of \\ Nutrition and Food Processing, Faculty of Al-Huson University College, Al-Balqa Applied University, Al-Salt, Jordan \\ Correspondence: Hiba Bawadi, Tel +974 4403 6586, Email hbawadi@qu.edu.qa
}

Background: Nutrition therapy is considered a key component of diabetes management. Recently, high-protein diets have gained in popularity. Understanding the glycemic effect of dietary protein among patients with diabetes has been of particular interest.

Methods: This study is based on NHANES data of 990 participants aged 40 years and older from the NHANES cohorts of 2011-2012 and 2013-2014 surveys. Glycosylated hemoglobin (HbA1c level) was used as indicator of glycemic control. Patients were categorized into quartiles for daily protein intake. Average protein intakes for patients in quartile 1 to quartile 4 were $35.5 \mathrm{~g}, 58.7 \mathrm{~g}, 79.9 \mathrm{~g}$, and $131.6 \mathrm{~g}$, respectively. Covariates included in the analysis were gender, age, race, caloric intake, muscle strength, education, income, smoking, sedentary lifestyle, alcohol consumption, and BMI.

Results: After controlling for covariates, patients in quartile 4 of protein intake had $261 \%$ increased risk of poor glycemic control compared with those in quartile 1 (95\% CI: 1.29-5.30). The association was not attenuated after further control for insulin use $(\mathrm{OR}=$ 1.94; 95\% CI: 0.89-4.24). In conclusion, higher protein intake seems related to a worse glycemic control in diabetic subjects.

Keywords: protein intake, diabetes, insulin

\section{Introduction}

Nutrition therapy is one of the most important keys to diabetes management. There is good evidence that combined interventions, including following healthy dietary habits, behavior modifications, and practicing physical activity, can prevent the progression of insulin resistance to diabetes. ${ }^{1}$ Regarding dietary approaches, it has been shown that diets containing low carbohydrate, low to moderate fat, high protein, and low glycemic index effectively reduce the risk of diabetes and reduce weight. ${ }^{2}$ However, limited evidence on the optimal diet composition to prevent hyperglycemia in type 2 diabetes mellitus (T2DM) is available. ${ }^{3}$

A high-protein diet has been gaining attention in dietary changes to prevent T2DM. A study revealed that higher intake of plant proteins showed a negative association with the risk of developing T2DM in the Chinese population. ${ }^{4}$ The same study reported a significant and independent direct association between total protein and animal protein and T2DM risk in the "red meat" dietary pattern. However, the same study showed that in the "refined grains" dietary pattern, animal protein intake was associated with lower T2DM risk. ${ }^{4}$ However, it is still not clear why the findings on the association between consuming high-protein foods and T2DM risk are inconsistent.

Evidence proposes that high-protein intake is associated with an improvement in insulin resistance; however, the lipid profiles were not affected in the study population. ${ }^{5}$ Furthermore, Akhavan et al (2020) reported that a higher intake of animal protein can enhance the function of $\beta$-cell and reduce plasma triglycerides.

This inconsistency and discrepancy in the findings of the studies could be due to many aspects, including the methodology, the size of the sample, and other factors. Therefore, this study aimed to assess the possible association 
between protein consumption and glycemic control with and without insulin use based on NHANES data collected on participants with T2DM aged above 40 years who were in the cohorts of the 2011-2012 and 2013-2014 surveys.

\section{Methods}

\section{Study Design and Subjects}

The data of the present study were obtained from the continuous National Health and Nutrition Examination Survey (NHANES) in 2011-2012 and 2013-2014. The NHANES is a multistage probability cross-sectional survey that studies the general nutritional and health status of the noninstitutionalized population of the United States (US). Around 5000 individuals were annually analyzed in the NHANES to assess the nutrition and health-related status. The total number of participants was 19,931; however, participants whose data were missing, who were not eligible, or were pregnant were excluded. The final sample size of the participants was 990. Only participants who were aged above 40 years and followed in both cohorts (2011-2012 and 2013-2014) were enrolled in this study. The flow-chart of the sample selection is provided in Figure 1. The nutrients intake was collected using 24-hour dietary recall, which was measured in two occasions.

The data was collected via face-to-face interviews and examinations on multiple demographic data of participants (family and individuals) about age, gender, race, education level, and income, and other related information obtained through standardized questions. For biochemical assessment, blood samples were collected from each participant. The NHANES data on HbAlc, body mass index (BMI), handgrip strength, and physical activity with known diabetic cases were involved in the current study. NHANES protocols and consent forms were approved by the NCHS Research Ethics Review Board (protocol \# 2011-17).

\section{Independent Variable}

\section{Protein Intake}

In the NHANES study, food intake for two nonconsecutive days was assessed via interviews. The first interview was conducted face to face, and the second interview was conducted via a phone call. The participants provided details of the meals they consumed in the past 24 hours, and each nutrient was estimated using the Food and Nutrient Database for

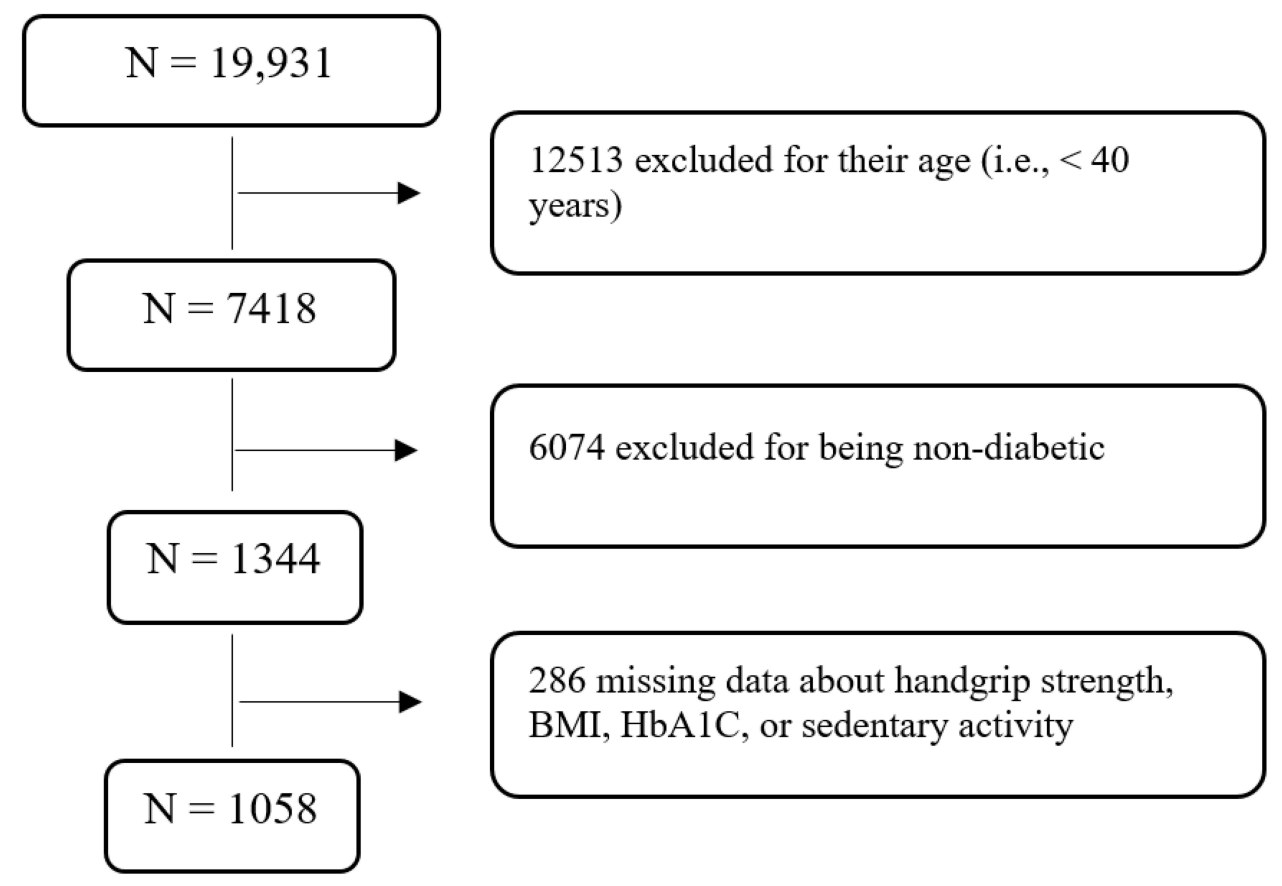

Figure I Flow-chart of study design. 
Dietary Studies published by the US Department of Agriculture (USDA). ${ }^{6}$ In our analysis, protein intake data were based on the face-to-face interview.

\section{Dependent Variable}

\section{Glycemic Control}

Glycemic control among T2DM patients was considered the dependent variable for this study, and HbA1c was used as the indicator of glycemic control. HbAlc can be used as a biomarker for glycemic control. ${ }^{7} \mathrm{HbAlc}$ rises in response to a high-fat diet, smoking, ${ }^{8,9}$ and body fat in diabetic patients. ${ }^{10} \mathrm{HbA} 1 \mathrm{c}$ above $7 \%$ was considered as an indicator of poor glycemic control. ${ }^{7}$

\section{Covariates}

The main covariates that were adjusted for in this study included body weight, height, BMI, physical activity, use of insulin, income-to-poverty ratio, smoking status, alcohol use and muscle strength.

\section{Body Weight, Height and BMI}

Height and body weight were estimated using standardized procedures. ${ }^{11}$ A standard digital scale was used to assess the weight of participants, and a stadiometer was used to measure their standing stature. After recording the two measurements (height and weight), the BMI was calculated as kilograms of body weight divided by height in square meters $\left(\mathrm{kg} / \mathrm{m}^{2}\right)$ for each participant.

\section{Physical Activity}

The physical activity examination was conducted via face-to-face interview. Participants were asked to answer either "yes" or "no" regarding whether they considered their usual physical activity per week to be vigorous or moderate. They were also asked to report the time they spent in a sedentary position on a typical day. If an individual reported practicing activities such as running or basketball for a minimum of 10 minutes per day, their physical activity level was defined as vigorous. The moderate physical activity level covered activities such as cycling, volleyball, swimming, or brisk walking for at least 10 minutes a day. ${ }^{12}$

\section{Use of Insulin}

Insulin use was reported from each participant and documented by asking the participants whether they used insulin or not.

\section{Income-to-Poverty Ratio}

Family income was obtained, and the federal income-to-poverty ratio for each participant was calculated.

\section{Smoking Status}

Participants were asked about their history of smoking (specifically cigarette use). Smoking was categorized as never, former, and current smoker. Former smoker was defined as smoking at least 100 cigarettes in life but does not currently smoke. The skilled interviewer used the computer-assisted personal interview (CAPI) system in the participant's home.

\section{Alcohol Use}

The alcohol questionnaire (ALQ) was applied to measure lifetime and current alcohol use but did not target the type of alcohol consumed by the study participants. The ALQ was administered at a mobile examination center. For adults aged above 18 years, questions were asked by trained interviewers using the CAPI system.

\section{Chronic Kidney Disease}

The CKD-EPI creatinine equation was used to estimate eGFR. ${ }^{28} \mathrm{CKD}$ was defined as eGFR $<60 \mathrm{~mL} / \mathrm{min} / 1.73 \mathrm{~m}^{2} .{ }^{13}$

\section{Muscle Strength}

Muscle strength refers to the ability of the body to perform certain activities, such as moving, pushing, pulling, and lifting. ${ }^{14}$ The handgrip test was applied using a handgrip dynamometer to measure muscle strength. The combined grip strength was used (the addition of the largest reading from each hand) and is expressed in kilograms. The procedure of 
the measurement was explained, and a complete demonstration was provided to the participants prior to the measurements being recorded by the examiner. The assessment was performed, while the patient was standing, and each participant was asked to squeeze the dynamometer and exhale while squeezing to prevent a rise in intrathoracic pressure. Participants with any past conditions that could affect their grip strength were identified and excluded. The grip size of the dynamometer was adjusted according to the participant's hand size. Each participant was asked to perform the procedure once before the actual reading was taken. Then, the same procedure was applied for the other hand of the participant, who was randomly assigned to start the test. The procedure tested each hand three times, with hands alternating between trials. A 60 -second rest was taken between each trial for the same hand. ${ }^{15}$

\section{Statistical Analysis}

Descriptive analysis was used to determine the mean (standard deviation) for all the continuous variables, and frequency was used to describe the discrete variables. ANOVA or chi-square tests were used to test the differences between groups of protein intake for continuous or categorical variables. Protein intake was recoded into quartiles. The first quartile (low intake) was used as the reference group. Survey weights, sample strata, and sample clusters were incorporated into the survey statistical procedures (using the svy command in Stata) to account for the complex multistage probability sampling. Four logistic regression models were used to investigate the association between poor glycemic control and protein intake. The first model adjusted for age, gender, and race. Model 2 further adjusted for sedentary activity, incometo-poverty ratio, education, smoking, alcohol consumption, handgrip strength (quartile) and BMI. Whereas model 3 further adjusted for insulin use, other medication for diabetes, and the duration of diabetes. Model 4 was based on model 3 but excluded those with CKD.

\section{Results}

Table 1 shows the sample characteristics based on the protein intake quartiles. The mean protein intake increased from $35.5 \mathrm{~g} / \mathrm{d}$ to $131.6 \mathrm{~g} / \mathrm{d}$ in the first and fourth quartiles of protein intake. Across the quartiles of protein intake, the intake of energy and other macronutrients increased, but the mean age decreased. There was no difference in race, education, BMI, sedentary activity, and smoking across the quartiles of protein intake. More than $25 \%$ of the participants reported using insulin.

After adjusting for sociodemographic and lifestyle factors, muscle strength, energy intake, and BMI, there was a dose-response positive relationship between protein intake and poor glycemic control with odds ratios (ORs) of 1.00, $1.68,1.62$, and 2.62 (95\% confidence interval [CI]: 1.29-5.33) across the quartiles of protein intake (p for trend 0.25) (Table 2). The association was attenuated and became non-statistically significant after further adjusting for insulin use, other medications for diabetes and the duration of diabetes. However, when we excluded those with CKD, high intake of protein was positively associated with poor glycemic control.

Figure 2 shows that the positive association between protein intake and poor glycemic control was only seen among insulin users. There was no association between protein intake, gender, and hypertension and poor glycemic control (data not shown).

\section{Discussion}

In this NHANES multistage probability cross-sectional survey conducted on 1058 self-reported individuals with type 1 and type 2 diabetes and aged 40 years or older, the main findings showed that there were no statistically significant $(\mathrm{p}>$ 0.05) differences in the individual's protein intake quartiles and poor glycemic control, but there was a reverse correlation between protein intake and glycemic control. However, this correlation was more obvious among insulin users and disappeared after further adjustment for insulin use in the logistic regression model that measured the association between protein intake quartiles and poor glycemic control. After adjusting for sociodemographic and lifestyle factors, muscle strength, energy intake, and BMI, individuals in quartile 4 of protein intake were 2.61 times more likely to have poor glycemic control. Furthermore, protein intake was significantly and proportionally correlated with carbohydrates, fat and energy intake and negatively correlated with age. Moreover, the handgrip strength increased as the protein intake quartile increased. 
Table I Sample Characteristics by Quartiles of Protein Intake $(N=990)$

\begin{tabular}{|c|c|c|c|c|c|}
\hline & QI & Q2 & Q3 & Q4 & p-value \\
\hline & $N=248$ & $N=247$ & $N=248$ & $N=247$ & \\
\hline Handgrip strength $(\mathrm{Kg})$ & $54.8(17.9)$ & $62.2(21.3)$ & $64.6(18.3)$ & $73.8(21.6)$ & $<0.001$ \\
\hline Age (years) & $64.6(10.5)$ & 63.7 (10.9) & $62.5(11.2)$ & $59.5(11.0)$ & $<0.001$ \\
\hline Gender & & & & & $<0.001$ \\
\hline Men & 75 (30.2\%) & II 6 (47.0\%) & $|3|$ (52.8\%) & 188 (76.1\%) & \\
\hline Women & $173(69.8 \%)$ & $|3|(53.0 \%)$ & 117 (47.2\%) & 59 (23.9\%) & \\
\hline Race & & & & & 0.47 \\
\hline NH White & $84(33.9 \%)$ & $89(36.0 \%)$ & 101 (40.7\%) & $89(36.0 \%)$ & \\
\hline $\mathrm{NH}$ Black & $86(34.7 \%)$ & $76(30.8 \%)$ & $61(24.6 \%)$ & $73(29.6 \%)$ & \\
\hline Mex American & $30(12.1 \%)$ & $32(13.0 \%)$ & $32(12.9 \%)$ & 40 (16.2\%) & \\
\hline Other race/ethn & $48(19.4 \%)$ & $50(20.2 \%)$ & $54(21.8 \%)$ & 45 (18.2\%) & \\
\hline Education & & & & & 0.10 \\
\hline$<$ II grade & $92(37.2 \%)$ & $84(34.1 \%)$ & 71 (28.6\%) & $63(25.5 \%)$ & \\
\hline HS displ or GED & $57(23.1 \%)$ & $51(20.7 \%)$ & $64(25.8 \%)$ & $60(24.3 \%)$ & \\
\hline Some College & $68(27.5 \%)$ & $70(28.5 \%)$ & 71 (28.6\%) & 71 (28.7\%) & \\
\hline$>$ college & $30(12.1 \%)$ & $41(16.7 \%)$ & $42(16.9 \%)$ & $53(21.5 \%)$ & \\
\hline Smoking & & & & & 0.26 \\
\hline Never & 135 (54.4\%) & $122(49.4 \%)$ & 122 (49.2\%) & $108(43.7 \%)$ & \\
\hline Former & $74(29.8 \%)$ & $85(34.4 \%)$ & $93(37.5 \%)$ & 96 (38.9\%) & \\
\hline Current smoker & $39(15.7 \%)$ & $40(16.2 \%)$ & $33(13.3 \%)$ & $43(17.4 \%)$ & \\
\hline Alcohol drinking & & & & & $<0.001$ \\
\hline No & $80(32.3 \%)$ & $67(27.1 \%)$ & $84(33.9 \%)$ & 67 (27.1\%) & \\
\hline Yes & 101 (40.7\%) & $128(51.8 \%)$ & 127 (51.2\%) & 142 (57.5\%) & \\
\hline Missing & $67(27.0 \%)$ & $52(21.1 \%)$ & 37 (14.9\%) & $38(15.4 \%)$ & \\
\hline BMI (kg/m2) & $32.2(7.2)$ & $31.9(7.1)$ & $32.8(7.4)$ & $32.3(7.3)$ & 0.59 \\
\hline BMI categories & & & & & 0.76 \\
\hline Underweight & $2(0.8 \%)$ & $0(0.0 \%)$ & $\mathrm{I}(0.4 \%)$ & $0(0.0 \%)$ & \\
\hline Normal & $29(11.7 \%)$ & $36(14.6 \%)$ & $33(13.3 \%)$ & $30(12.1 \%)$ & \\
\hline Overweight & $72(29.0 \%)$ & $70(28.3 \%)$ & $70(28.2 \%)$ & $80(32.4 \%)$ & \\
\hline Obese & 145 (58.5\%) & $14 \mid(57.1 \%)$ & 144 (58.1\%) & 137 (55.5\%) & \\
\hline Sedentary activity & & & & & 0.74 \\
\hline$\leq 3 \mathrm{hrs}$ & $50(20.2 \%)$ & $50(20.2 \%)$ & $38(15.3 \%)$ & $44(17.8 \%)$ & \\
\hline $3-6 \mathrm{hrs}$ & 79 (31.9\%) & 79 (32.0\%) & 79 (31.9\%) & $74(30.0 \%)$ & \\
\hline $6+\mathrm{hrs}$ & $119(48.0 \%)$ & $118(47.8 \%)$ & $|3|(52.8 \%)$ & $129(52.2 \%)$ & \\
\hline Income to poverty ratio & & & & & 0.056 \\
\hline$<1.30$ & $104(46.0 \%)$ & $84(36.5 \%)$ & $85(36.2 \%)$ & $76(32.6 \%)$ & \\
\hline $1.3-3.5$ & $84(37.2 \%)$ & $88(38.3 \%)$ & 95 (40.4\%) & 94 (40.3\%) & \\
\hline$>3.5$ & $38(16.8 \%)$ & $58(25.2 \%)$ & $55(23.4 \%)$ & $63(27.0 \%)$ & \\
\hline HbAlc (\%) & $7.2(1.8)$ & $7.4(1.8)$ & $7.5(1.9)$ & $7.6(1.7)$ & 0.20 \\
\hline Poor glycemic control & $112(45.2 \%)$ & $115(46.6 \%)$ & $116(46.8 \%)$ & 137 (55.5\%) & 0.087 \\
\hline Diabetes duration (years) & $13.1(10.3)$ & $12.2(10.7)$ & $10.9(9.7)$ & $10.7(10.4)$ & 0.032 \\
\hline Hypertension & 179 (74.6\%) & $176(72.7 \%)$ & 175 (71.7\%) & 169 (69.0\%) & 0.58 \\
\hline CVD & $97(39.1 \%)$ & $73(29.6 \%)$ & $66(26.6 \%)$ & $46(18.6 \%)$ & $<0.001$ \\
\hline Use insulin & $65(26.2 \%)$ & $72(29.1 \%)$ & $64(25.8 \%)$ & $73(29.6 \%)$ & 0.70 \\
\hline Taking diabetic pills & $183(73.8 \%)$ & $177(7 \mid .7 \%)$ & $174(70.2 \%)$ & 178 (72.7\%) & 0.83 \\
\hline
\end{tabular}

Recent results from a systemic and meta-analysis of randomized controlled trials review revealed that a highprotein diet does not significantly ameliorate blood glucose and blood pressure levels, although it improves the HOMA-IR, triglycerides, total cholesterol, and low-density lipoprotein cholesterol (LDL-C) levels. Also, it did not show any significant effect on the long-term index of $\mathrm{HbA} 1 \mathrm{c} \%$ due to the short duration of protein intake. ${ }^{16}$ The reported findings regarding high protein intake and $\mathrm{HbAlc} \%$ as a glycemic control are aligned with our findings. Furthermore, a study conducted in 2020 by Akhavan et al which stratified the protein intake of overweight or obese 
Table 2 Odds Ratio $(95 \% \mathrm{Cl})$ for Poor Glycemic Control by Quartiles of Protein Intake

\begin{tabular}{|c|c|c|c|c|c|c|c|c|}
\hline & \multicolumn{7}{|c|}{ Quartiles of Protein Intake } & \multirow[t]{2}{*}{$P$ for Trend } \\
\hline & QI & \multicolumn{2}{|r|}{ Q2 } & \multicolumn{2}{|r|}{ Q3 } & \multicolumn{2}{|r|}{ Q4 } & \\
\hline Model I & 1.00 & 1.37 & $(0.79-2.38)$ & 1.33 & $(0.7 I-2.49)$ & 2.32 & $(1.20-4.50)$ & 0.033 \\
\hline Model 2 & 1.00 & 1.68 & $(0.93-3.04)$ & 1.62 & $(0.78-3.38)$ & 2.62 & $(1.29-5.33)$ & 0.025 \\
\hline Model 3 & 1.00 & 1.35 & $(0.72-2.5 I)$ & 1.44 & $(0.63-3.32)$ & 1.70 & $(0.73-3.94)$ & 0.251 \\
\hline Model 4 & 1.00 & 1.59 & $(0.86-2.95)$ & 1.68 & $(0.75-3.76)$ & 2.55 & $(1.02-6.39)$ & 0.073 \\
\hline
\end{tabular}

Notes: Model I adjusted for age, gender, race and energy intake. Model 2 further adjusted for sedentary activity, income, education, smoking, BMI (continuous), handgrip strength (quartiles). Model 3 further adjusted for insulin use, medication for diabetes, and duration of diabetes. Model 4 excluded those with CKD.

prediabetic patients or patients with T2DM aged 45-75 years into, less than $0.8 \mathrm{~g} / \mathrm{kg}$ body weight, 0.8 to less than 1.0 $\mathrm{g} / \mathrm{kg}$ body weight, and more than or equal to $1.0 \mathrm{~g} / \mathrm{kg}$ body weight revealed that higher intake of animal protein was positively correlated with more secretion of insulin and decreasing the triglyceride level. This shows that $\beta$-cell function can be improved by increasing animal protein intake. ${ }^{5}$ Our results did not classify the individual's protein intake according to source (ie, animal or plant protein) or measure the $\beta$-cell function.

Dietary proteins stimulate the secretion of insulin and therefore reduce blood glucose levels. ${ }^{17}$ However, the effects of long and short-term consumption of high protein diets on insulin sensitivity in T2DM patients are indecisive. ${ }^{18,19}$ For instance, Weickert et al (2011) reported a reduction in insulin sensitivity among patients following high-protein (25-30\% of total energy) and low-carbohydrate (40-45\% of total energy) diet for 6 weeks. ${ }^{20}$ Whereas Gannon \& Nuttall demonstrated an improvement in insulin sensitivity after 5 weeks of following a high-protein (30\% of total energy), reduced-carbohydrate ( $20 \%$ of total energy) diet compared with normal protein and carbohydrate (15\% protein and $55 \%$ carbohydrate of total energy) diet in patients with $\mathrm{T}_{2} \mathrm{DM}^{21}{ }^{21}$ No significant remarkable differences were seen in the fasting insulin levels between the two diets. However, there was a reduction in fasting and postprandial blood glucose concentration using the same high-protein diet. ${ }^{22}$ In addition, it is difficult to determine the causal effect on insulin

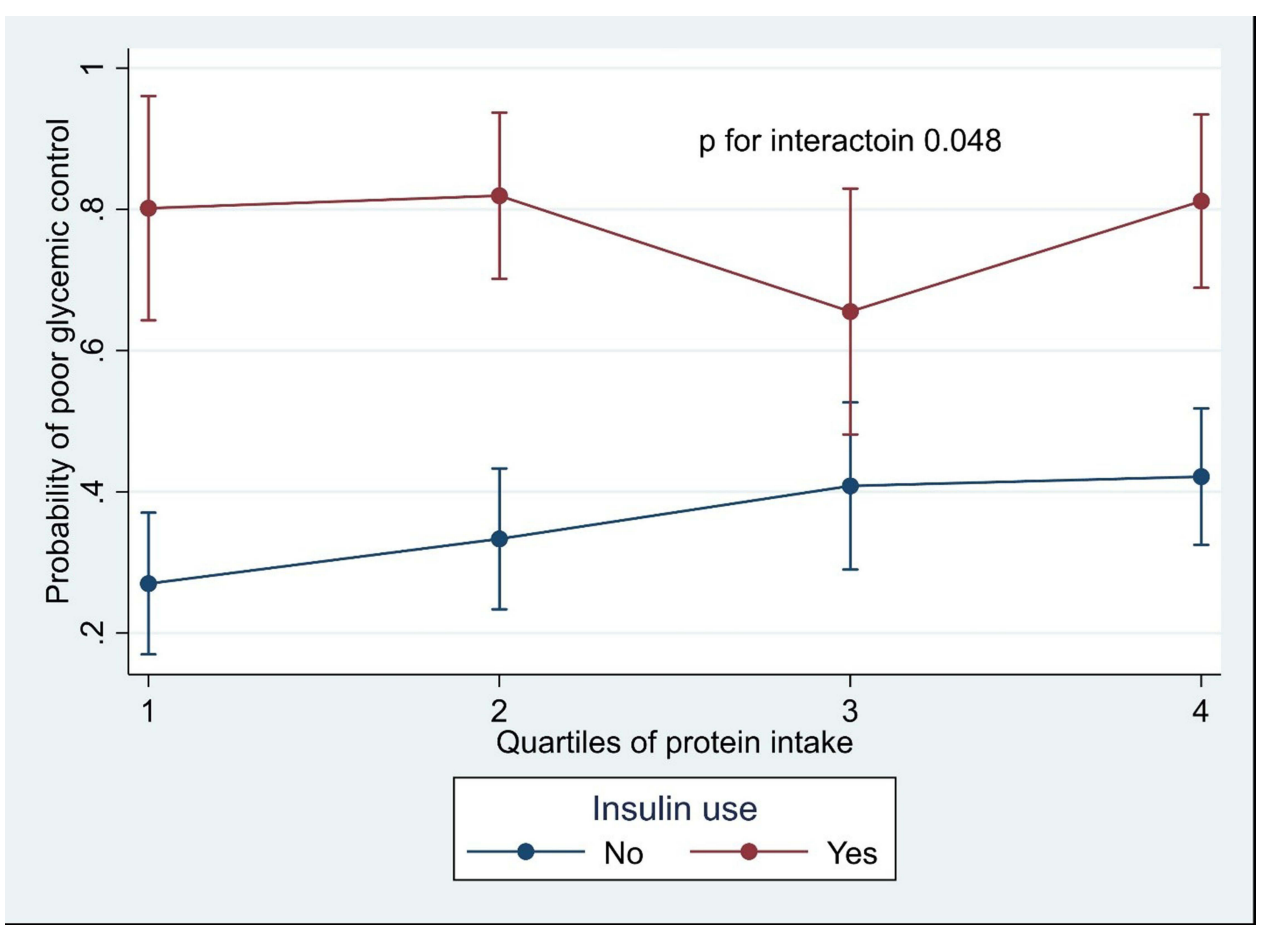

Figure 2 Interaction between insulin use and protein intake in relation to poor glycemic control.

Notes: Model adjusted for age, gender, race, energy intake, muscle strength, sedentary activity, income-to-poverty ratio, education, smoking, alcohol drinking, BMI, other medications for diabetes, and duration of diabetes. 
sensitivity when the dietary protein consumption is increased at the expenses of reducing the carbohydrate amount in the diet. $^{23}$ In this study, protein intake was determined based on a personal interview and 24-hour dietary intake. Among the quartile 4 protein intake group, the estimated average protein intake was $132 \mathrm{~g}$, which is around $19 \%$ of the average energy ( $2808 \mathrm{Kcal})$. This is not consistent with previous short-term protein intake studies but is aligned to some extent with the findings of Weickert et al (2011).

Higher dietary protein intake may worsen glycemic control through the ability of amino acids to impair glucose synthesis via the inhibition of glucose transportation and phosphorylation, leading to insulin resistance. Additionally, amino acids intervene with glucose metabolism through the initiation of insulin and glucagon secretion and through serving as substrates for gluconeogenesis. ${ }^{21}$

Previous intervention trials revealed that short-term high protein intake at the expense of carbohydrates improves glycemic control in patients with T2DM by stimulating insulin secretion during eating. ${ }^{24}$ Conversely, epidemiological studies propose that long-term high dietary protein intake is correlated with higher incidence of T2DM. ${ }^{25,26}$ Furthermore, short-term elevation of plasma amino acid concentrations encourages insulin resistance in skeletal muscle and enhances endogenous glucose synthesis through the glucose transport/phosphorylation suppression, which can cause significant reduction in glycogen production. Therefore, amino acids may participate in insulin resistance and may play a role in peripheral insulin sensitivity modulation. ${ }^{27}$ In this study, we did not measure the level of plasma amino acids to test its effect on insulin sensitivity.

Moreover, dietary proteins including a significant content of branched-chain amino acids (BCAA) were strongly associated with hyperinsulinemia, insulin resistance and diabetes. ${ }^{28,29}$ Although whey protein contains high levels of $\mathrm{BCAA}^{30}$ the relationship between insulin resistance and the BCAA plasma concentrations, which may reflect long-term dietary protein consumption, requires further investigation and discussion. ${ }^{31}$ Increased plasma BCAA can be a result of insulin resistance. This might be explained by the inhibition of the branched chain $\alpha$-ketoacid dehydrogenase (BCKD) via insulin, leading to inhibition in BCAA catabolism. ${ }^{32}$ Moreover, the mechanistic target of rapamycin (mTOR) can be activated by BCAA and other nutrients. This activation negatively affects the phosphorylation of the insulin receptor substrate 1 (IRS1), which leads to a reduction in insulin sensitivity. This indicates that there is a prospective link between insulin resistance and $\mathrm{BCAA} .{ }^{23} \mathrm{~A}$ mixed protein diet provides more than $20 \%$ of $\mathrm{BCAA},{ }^{33}$ although leucine supplementation for 6 months in elderly men with T2DM did not improve glycemic control. ${ }^{34}$ Unfortunately, our study did not consider the dietary or the plasma BCAA concentrations.

Bawadi et al examined the relationship between glycemic control and grip strength and reported no significant association. ${ }^{35}$ However, an association was present after adjusting for biological, behavioral, dietary, educational, and socioeconomic variables but disappeared after adjusting for insulin use. These results were promising, suggesting that insulin plays a role in grip strength. ${ }^{35}$ The same association was found in this study between the quartile 4 protein intake and poor glycemic control. As stated previously, the grip strength increased significantly as the dietary protein intake increased, which was associated with poor glycemic control.

Although our study included a large cohort, it has some limitations. First, the study was cross-sectional and thus did not allow us to make causal influences such as the influence of a high protein diet on glycemic control. Second, the use of 24-hour dietary intake and personal interview to identify protein intake increase the possibility of recall bias where the participating subjects may selectively recall food items. Third, all biochemical and physical parameters were performed only once, so some of these could be biased and can be changed by temporal diseases or clinical facts. Fourth, not all factors correlated with protein intake and glycemic control were taken into consideration when data were collected such as the sources or type of protein intake, duration, protein intake level according to RDA, plasma amino acid concentrations, insulin, and HOMA-IR.

In conclusion, high protein intake is associated with poor glycemic control as determined by the $\mathrm{HbA} 1 \mathrm{c} \%$ among insulin-treated patients with diabetes. The intermediate role of using insulin in the relationship between glycemic control and high protein intake in diabetic patients needs further investigations. 


\section{Acknowledgment}

The abstract of this paper was presented Qatar University Annual Research Forum and Exhibition (2020) as a poster presentation with interim findings. The poster's abstract was uploaded to the Qatar University repository: https://qspace. qu.edu.qa/handle/10576/16732 Reference. ${ }^{36}$ The APC charges were funded by QU-Health.

\section{Disclosure}

The authors report no conflicts of interest in this work.

\section{References}

1. Galaviz KI, Narayan KV, Lobelo F, et al. Lifestyle and the prevention of Type 2 Diabetes: a status report. Am J Lifestyle Med. 2018;12(1):4-20. doi:10.1177/1559827615619159

2. Malik VS, Popkin BM, Bray GA, et al. Sugar-sweetened beverages and risk of metabolic syndrome and type 2 diabetes: a meta-analysis. Diabetes Care. 2010;33(11):2477-2483. doi:10.2337/dc10-1079

3. Schwingshackl L, Hoffmann G. Comparison of the long-term effects of high-fat v. low-fat diet consumption on cardiometabolic risk factors in subjects with abnormal glucose metabolism: a systematic review and meta-analysis. Br j Nutrition. 2014;111(12):2047-2058. doi:10.1017/ S0007114514000464

4. Ke Q, Chen C, He F, et al. Association between dietary protein intake and type 2 diabetes varies by dietary pattern. Diabetol Metab Syndr. 2018;10 (1):48. doi:10.1186/s13098-018-0350-5

5. Akhavan NS, Pourafshar S, Johnson SA, et al. The Relationship between Protein Intake and Source on Factors Associated with Glycemic Control in Individuals with Prediabetes and Type 2 Diabetes. Nutrients. 2020;12(7):2031. doi:10.3390/nu12072031

6. Ahluwalia N, Dwyer J, Terry A, et al. Update on NHANES Dietary Data: focus on Collection, Release, Analytical Considerations, and Uses to Inform Public Policy. Adv Nutr. 2016;7(1):121-134. doi:10.3945/an.115.009258

7. Association AD. Diagnosis and classification of diabetes mellitus. Diabetes Care. 2013;36(Supplement 1):S67-S74. doi:10.2337/dc13-S067

8. Chang SA. Smoking and type 2 diabetes mellitus. Diabetes Metab J. 2012;36(6):399-403. doi:10.4093/dmj.2012.36.6.399

9. Lassiter TL, Ryde IT, MacKillop EA, et al. Exposure of neonatal rats to parathion elicits sex-selective reprogramming of metabolism and alters the response to a high-fat diet in adulthood. Environ Health Perspect. 2008;116(11):1456-1462. doi:10.1289/ehp.11673

10. Evangelista LS, Heber D, Li Z, et al. Reduced body weight and adiposity with a high-protein diet improves functional status, lipid profiles, glycemic control, and quality of life in patients with heart failure: a feasibility study. J Cardiovasc Nurs. 2009;24(3):207. doi:10.1097/ JCN.0b013e31819846b9

11. Ogden CL, Carroll MD, Lawman HG, et al. Trends in obesity prevalence among children and adolescents in the United States, 1988-1994 through 2013-2014. JAMA. 2016;315(21):2292-2299. doi:10.1001/jama.2016.6361

12. Li S, Zhang R, Pan G, et al. Handgrip strength is associated with insulin resistance and glucose metabolism in adolescents: evidence from National Health and Nutrition Examination Survey 2011 to 2014. Pediatr Diabetes. 2018;19(3):375-380. doi:10.1111/pedi.12596

13. Webster AC, Nagler EV, Morton RL, et al. Chronic Kidney Disease. Lancet. 2017;389(10075):1238-1252. doi:10.1016/S0140-6736(16)32064-5

14. Evans WJ. What is sarcopenia? J Gerontol a Biol Sci Med Sci. 1995;50:5-8. doi:10.1093/gerona/50A.Special_Issue.5

15. Prevention CfDCa. National Health and Nutrition Examination Survey 2013-2014; 2014.

16. Yu Z, Nan F, Wang LY, et al. Effects of high-protein diet on glycemic control, insulin resistance and blood pressure in type 2 diabetes: a systematic review and meta-analysis of randomized controlled trials. Clin Nutrition. 2020;39(6):1724-1734. doi:10.1016/j.clnu.2019.08.008

17. El Khoury D, Hwalla N. Metabolic and appetite hormone responses of hyperinsulinemic normoglycemic males to meals with varied macronutrient compositions. Ann Nutr Metab. 2010;57(1):59-67. doi:10.1159/000317343

18. Ricci G, Canducci E, Pasini V, et al. Nutrient intake in Italian obese patients: relationships with insulin resistance and markers of non-alcoholic fatty liver disease. Nutrition. 2011;27(6):672-676. doi:10.1016/j.nut.2010.07.014

19. Sluijs I, Beulens JW, Spijkerman AM, et al. Dietary intake of total, animal, and vegetable protein and risk of type 2 diabetes in the European Prospective Investigation into Cancer and Nutrition (EPIC)-NL study. Diabetes Care. 2010;33(1):43-48. doi:10.2337/dc09-1321

20. Weickert MO, Roden M, Isken F, et al. Effects of supplemented isoenergetic diets differing in cereal fiber and protein content on insulin sensitivity in overweight humans. Am J Clin Nutr. 2011;94(2):459-471. doi:10.3945/ajen.110.004374

21. Gannon MC, Nuttall FQ. Effect of a high-protein, low-carbohydrate diet on blood glucose control in people with type 2 diabetes. Diabetes. 2004;53 (9):2375-2382. doi:10.2337/diabetes.53.9.2375

22. Nuttall FQ, Schweim K, Hoover H, et al. Effect of the LoBAG 30 diet on blood glucose control in people with type 2 diabetes. Br $j$ Nutrition. 2008;99(3):511-519. doi:10.1017/S0007114507819155

23. Rietman A, Schwarz J, Tomé D, et al. High dietary protein intake, reducing or eliciting insulin resistance? Eur J Clin Nutr. 2014;68(9):973-979. doi:10.1038/ejen.2014.123

24. Promintzer M, Krebs M. Effects of dietary protein on glucose homeostasis. Curr Opin Clin Nutr Metab Care. 2006;9(4):463-468. doi:10.1097/01. mco.0000232909.84483.a9

25. Shang X, Scott D, Hodge AM, et al. Dietary protein intake and risk of type 2 diabetes: results from the Melbourne Collaborative Cohort Study and a meta-analysis of prospective studies. Am J Clin Nutr. 2016;104(5):1352-1365. doi:10.3945/ajcn.116.140954

26. Van Nielen M, Feskens EJ, Mensink M, et al. Dietary protein intake and incidence of type 2 diabetes in Europe: the EPIC-InterAct Case-Cohort Study. Diabetes Care. 2014;37(7):1854-1862. doi:10.2337/dc13-2627

27. Krebs M, Krssak M, Bernroider E, et al. Mechanism of amino acid-induced skeletal muscle insulin resistance in humans. Diabetes. 2002;51 (3):599-605. doi:10.2337/diabetes.51.3.599

28. Newgard CB, An J, Bain JR, et al. A branched-chain amino acid-related metabolic signature that differentiates obese and lean humans and contributes to insulin resistance. Cell Metab. 2009;9(4):311-326. doi:10.1016/j.cmet.2009.02.002 
29. Wang TJ, Larson MG, Vasan RS, et al. Metabolite profiles and the risk of developing diabetes. Nat Med. 2011;17(4):448-453. doi:10.1038/nm.2307

30. Nilsson M, Stenberg M, Frid AH, et al. Glycemia and insulinemia in healthy subjects after lactose-equivalent meals of milk and other food proteins: the role of plasma amino acids and incretins. Am J Clin Nutr. 2004;80(5):1246-1253. doi:10.1093/ajcn/80.5.1246

31. Würtz P, Mäkinen V-P, Soininen P, et al. Metabolic signatures of insulin resistance in 7098 young adults. Diabetes. 2012;61(6):1372-1380. doi:10.2337/db11-1355

32. Adams SH. Emerging perspectives on essential amino acid metabolism in obesity and the insulin-resistant state. Advances in Nutrition. 2011;2 (6):445-456. doi:10.3945/an.111.000737

33. Ouellet V, Marois J, Weisnagel SJ, et al. Dietary cod protein improves insulin sensitivity in insulin-resistant men and women: a randomized controlled trial. Diabetes Care. 2007;30(11):2816-2821. doi:10.2337/dc07-0273

34. Leenders M, Verdijk LB, van der Hoeven L, et al. Prolonged leucine supplementation does not augment muscle mass or affect glycemic control in elderly type 2 diabetic men. $J$ Nutr. 2011;141(6):1070-1076. doi:10.3945/jn.111.138495

35. Bawadi H, Alkhatib D, Abu-Hijleh H, et al. Muscle Strength and Glycaemic Control among Patients with Type 2 Diabetes. Nutrients. 2020;12 (3):771. doi:10.3390/nu12030771

36. Bawadi H, Shi Z. Protein Intake Among Patients with Diabetes is Linked Poor Glycemic Control. Doha: Qatar University Annual Research Forum and Exhibition. Qatar; 2020.

Diabetes, Metabolic Syndrome and Obesity: Targets and Therapy

\section{Publish your work in this journal}

Diabetes, Metabolic Syndrome and Obesity: Targets and Therapy is an international, peer-reviewed open-access journal committed to the rapid publication of the latest laboratory and clinical findings in the fields of diabetes, metabolic syndrome and obesity research. Original research, review, case reports, hypothesis formation, expert opinion and commentaries are all considered for publication. The manuscript management system is completely online and includes a very quick and fair peer-review system, which is all easy to use. Visit http://www.dovepress. com/testimonials.php to read real quotes from published authors.

Submit your manuscript here: https://www.dovepress.com/diabetes-metabolic-syndrome-and-obesity-targets-and-therapy-journal 